\title{
A DOUBLE-BLIND COMPARISON OF BUTORPHANOL AND MEPERIDINE IN LABOUR: MATERNAL PAIN RELIEF AND EFFECT ON THE NEWBORN
}

\author{
Albert L. Maduska and Mehrdokht Hajghassemali
}

Several ATtempts have been made in recent years to obtain an agent which is a potent analgesic with reduced potential for physical dependence that could be totally synthesized without dependence on a supply of opium. Several years ago a series of benzomorphans were synthesized which combine analgesic with narcotic antagonistic properties. Several of these compounds were acceptable analgesics, except that various psychomimetic effects accompanied their use. ${ }^{1.2}$

In 1973, Monkovic reported the synthesis of butorphanol. ${ }^{3}$ Studies with this drug in animals and man have demonstrated significant analgesic potency, narcotic antagonistic properties, an antitussive effect, reversibility with naloxone and indications that the physical dependence liability was very low. ${ }^{4,5}$ Several studies in particular have indicated that it is safe and effective in relieving post-operative pain. In these studies the potency of butorphanol was found to be approximately five times that of morphine and 40 times that of meperidine ${ }^{6-8}$

In studies at Bristol Laboratories, butorphanol did not cause any teratological abnormalities in rats and rabbits that could be attributed to the drug. In rats which received butorphanol during pregnancy and up to day 21 postpartum it had no discernible effect on the condition of the dams, parturition, delivery, perinatal weight or nursing instincts and there was no variation of post-natal weight or viability of the pups.

The objective of this study was to evaluate the intramuscular analgesic properties, effect on the progress of labour, condition of the newborn and any side effects of butorphanol tartrate $1 \mathrm{mg}$ and 2 $\mathrm{mg}$ (as salt) compared to meperidine $\mathbf{4 0} \mathrm{mg}$ and 80 $\mathrm{mg}$ (as salt) in a double-blind randomized study employing hospitalized obstetrical patients at

Albert L. Maduska, M.D., Professor, Mehrdokht Hajghassemali, M.D., Instructor, Department of Anesthesiology, University of Tennessee; Center for the Health Sciences, Memphis, Tennessee, 38163.

Supported by a grant from Bristol Laboratories. Syracuse, New York. term who were having moderate to severe prepartum labour pain.

Approval for this study was obtained from the Food and Drug Administration and the Committee on Human Experimentation at the University of Tennessee Center for the Health Sciences.

\section{Methods and Materials}

After giving informed consent, eighty normal mothers at term and in active labour with moderate to severe pain chose to enter the study. Prenatal care was adequate in every case. There was no history of drug use other than routine prenatal drugs. Women with systemic disease and mothers intending to nurse their baby were excluded from the study.

After total randomization and preparation, the test drugs were provided in identical vials * which were numbered consecutively and assigned to the patients in the order of their entrance to the study. Each patient received intramuscularly an injection of meperidine $40 \mathrm{mg}$, butorphanol $1 \mathrm{mg}$, meperid ine $80 \mathrm{mg}$, or butorphanol $2 \mathrm{mg}$.

Previous studies have indicated that butorphanol $1 \mathrm{mg}$ and meperidine $40 \mathrm{mg}$ were equally analgesic; and that butorphanol $2 \mathrm{mg}$ and meperidine $80 \mathrm{mg}$ gave greater pain relief but were also essentially equi-analge sic. ${ }^{8}$ Pain intensity scores by the observers (authors) were recorded at 30 minutes and one hour as follows: $1=$ slight pain; 2 = moderate pain or $3=$ severe pain. Pain relief scores were provided by the patient at 30 minutes and one hour and were scaled as: $0=$ no relief; $t=$ slight relief; $2=$ moderate relief; $3=$ good relief; $4=$ complete relief. A pain intensity difference score was computed at the time of analysis by subtracting each of the postmedication pain intensity scores from their respective initial pain intensity score. Patients were allowed a second equal dose of their original drug after one hour if pain was severe and if they requested additional medication.

*Provided by Bristol Laboratories. 
All side effects observed or reported were recorded throughout the study.

Arterial blood was drawn and $\mathrm{pH}$ and blood gases were measured on the first 20 mothers at one hour after the initial dose. All foetuses were monitored by electrocardiograph. Uterine tone was evaluated when possible. The patient was delivered with local or regional anaesthesia. A postpartum interview was done after the patient had left the delivery room. Patients were questioned about psychomimetic phenomena such as hallucinations and unpleasant subjective experiences and were asked to provide a rating of the overall drug effect (efficacy and side effects) at the end of the study as follows: $1=$ poor, 2 = fair, $3=$ very good, or $4=$ excellent.

In addition to time from administration of the analgesic to delivery and foetal monitoring, the following data were obtained for the infant: weight, sex and Apgar scores at one minute and five minutes. ${ }^{9}$ The condition of the infant was determined by the total Apgar score, which consists of the objective record of its heart rate, promptness and vigour of the first respiratory efforts, response to stimulation, muscle tone and colour. Each of these are scored 0,1 or 2 , so the perfectly normal infant received an Apgar score of 10 . The time from delivery to sustained respiration, umbilical venous $\mathrm{H}^{+}(\mathrm{pH})$ and $\mathrm{P}_{\mathrm{CO}_{2}}$, general condition of the infant and general nursery survey were also recorded.

\section{RESULTS}

There was little difference among test groups with respect to type of labour, weight, age, type of delivery and anaesthetic agent administered. Other demographic characteristics were also similar, except that the butorphanol $1 \mathrm{mg}$ group had a slightly lower mean body weight. There were 77 black and three white patients. Ninetythree per cent had spontaneous labours and six per cent had inductions. Seventy-five per cent were delivered with forceps, 20 per cent delivered spontaneously and five per cent required Caesarian section. The indications for Caesarian section were not drug-related.

\section{Maternal results}

All treatment groups demonstrated some degree of efficacy in pain relief. Analysis was done to compare butorphanol with meperidine, the drug most commonly used for relief of prepartum pain. Analysis of variance and Duncan's new multiple-range test (NMR) did not detect any significant differences between treatment means of pain intensity or pain intensity difference scores. ${ }^{*}$ These observer scores indicated that the two compounds were effective in providing pain relief (Table I). However, statistical analysis of the means of pain relief score and the means of global score did detect a significant difference between the drugs $(p<0.05)$. With respect to pain relief, both butorphanol $2 \mathrm{mg}$ and meperidine $80 \mathrm{mg}$ were significantly better than meperidine $40 \mathrm{mg}$. One-half hour after the first dose, pain relief scores were significantly greater for butorphanol $2 \mathrm{mg}$ than for meperidine $40 \mathrm{mg}$ $(p<0.05$ ). At one hour after the first dose all other treatments gave significantly greater pain relief than did meperidine $40 \mathrm{mg}(p<0.05$ ). Tests on one hour sums of pain relief indicated that butorphanol $2 \mathrm{mg}$ and meperidine $80 \mathrm{mg}$ produced significantly more pain relief than did meperidine $40 \mathrm{mg}$ ( $\mathrm{p}<0.05$ )

Analysis of global scores by Duncan's NMR test revealed that butorphanol $2 \mathrm{mg}$ and meperidine $80 \mathrm{mg}$ were rated significantly higher than meperidine $40 \mathrm{mg}(p<0.05)$. (Table I). At the post-partum interview no patient complained of psychomimetic phenomena.

The data support a 1:40 butorphanol to meperidine potency ratio as reported previously. ${ }^{8}$ Thirty-six of the 80 patients requested a second dose of medication. The number from each group requesting a second dose was not significantly different: butorphanol $1 \mathrm{mg}(\mathrm{N}=8)$, meperidine $40 \mathrm{mg}(\mathrm{N}=9)$, meperidine $80 \mathrm{mg}(\mathrm{N}=$ 10) and butorphanol $2 \mathrm{mg}(\mathrm{N}=9)$.

With the second dose, the one-hour pain relief scores indicated that meperidine $80 \mathrm{mg}$ produced significantly more relief than either meperidine $\mathbf{4 0}$ $\mathrm{mg}$ or butorphanol $1 \mathrm{mg}$ ( $\mathrm{p}<0.05$ ). At one hour after the second dose butorphanol $2 \mathrm{mg}$ gave significantly greater pain relief than butorphanol 1 $\mathrm{mg}(\mathrm{p}<0.05)$. Because of the small numbers of second dose subjects, no other significant differences could be shown.

The time differences in minutes from onset of first stage to drug administration and from drug administration to stage 2 and delivery were not different for the four treatment groups. Most patients were delivered with regional or local analgesia. Two of four patients who had a Caesarian section were delivered under general anaesthesia.

* Statistical analyses were done by the TIS Section of the Mead Johnson Co. 


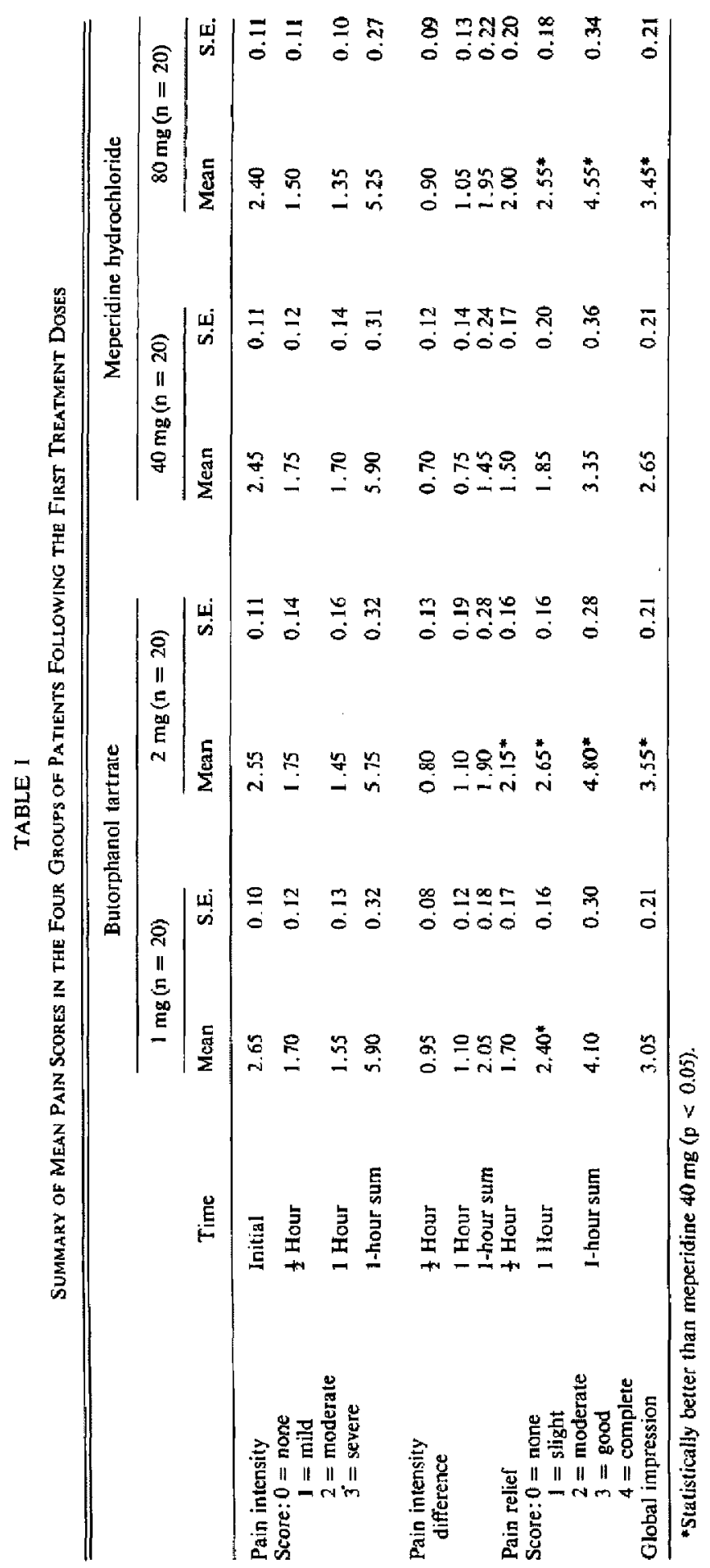




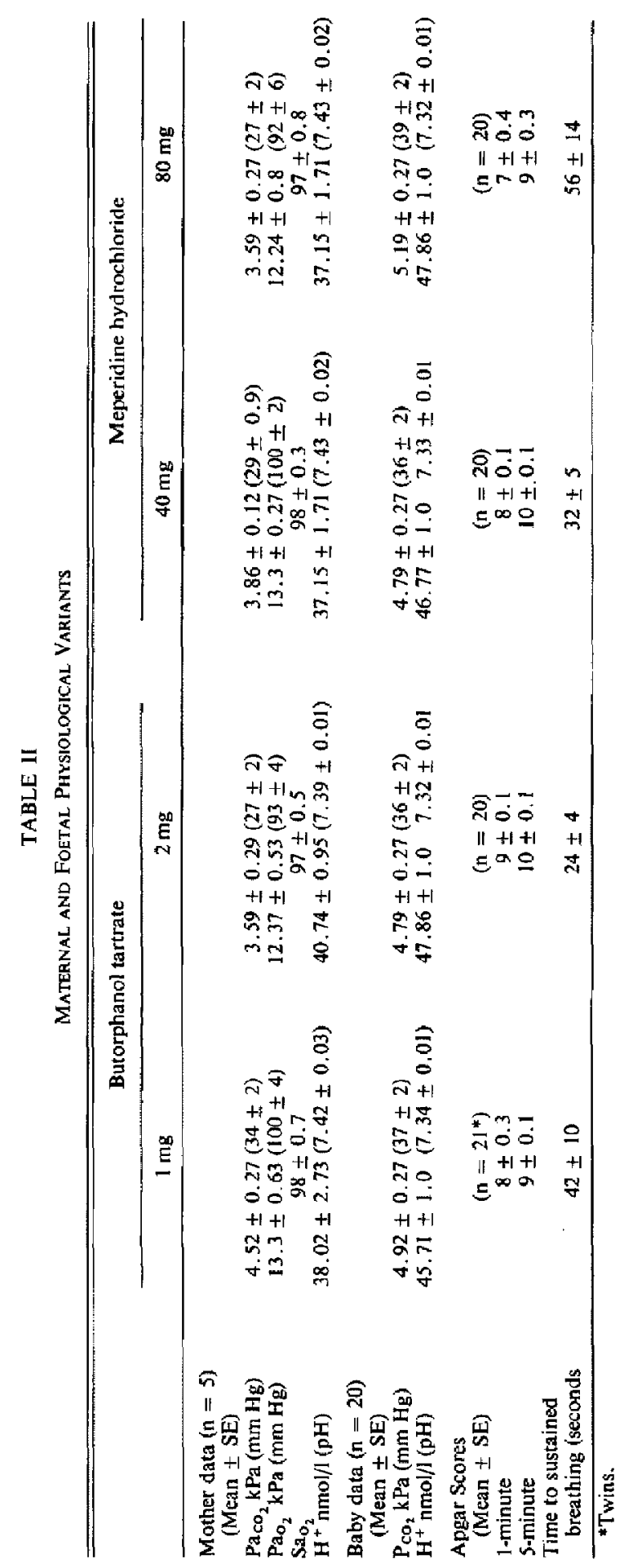


TABLE III

Maternal, and Neonatal Serum Level Data (Means)

\begin{tabular}{|c|c|c|c|c|c|}
\hline \multirow[b]{2}{*}{ Treatment } & \multirow{2}{*}{$\begin{array}{l}\text { Number } \\
\text { of } \\
\text { samples }\end{array}$} & \multirow{2}{*}{$\begin{array}{l}\text { Time of sample } \\
\text { collection } \\
\text { following dose }\end{array}$} & \multicolumn{2}{|c|}{$\begin{array}{c}\text { Serum levels } \\
\mathrm{ng} / \mathrm{ml}\end{array}$} & \multirow{2}{*}{$\begin{array}{l}\text { Neonatal: } \\
\text { maternal } \\
\text { ratio }\end{array}$} \\
\hline & & & Maternal & Neonatal & \\
\hline Butorphanol & $6^{*}$ & 128 minutes & 0.76 & 0.64 & 0.84 \\
\hline Meperidine & $4 t$ & 121 minutes & 132 & 126 & 0.89 \\
\hline
\end{tabular}

* 3 patients - one dose of $1 \mathrm{mg}$.

1 patient - one dose of $2 \mathrm{mg}$.

1 patient - two doses of $1 \mathrm{mg}$.

1 patient - two doses of $2 \mathrm{mg}$.

$\uparrow 2$ patients - one dose of $40 \mathrm{mg}$.

2 patients - two doses of $40 \mathrm{mg}$.

The arterial blood gases drawn on the first 20 mothers ( 5 per treatment group) were analyzed for $\mathrm{Pa}_{\mathrm{O}_{2}}, \mathrm{~Pa}_{\mathrm{CO}_{2}}, \mathrm{pH}$ and $\mathrm{Sa}_{\mathrm{O}_{2}}$. Analysis of variance did not detect any significant difference between treatment means (Table II).

Foetal electrocardiographic monitoring during labour did not detect any significant drug-related changes in foetal heart rate variability or uterine tone. Slight decreases in foetal heart rate variability were often seen after treatment in all four groups. These were typical of the diminished beat-to-beat variability seen commonly with this class of drugs.

There were no prohibitive drug-related side effects. Sixty-seven per cent of the patients had no side effects. In the others sedation was the most common side effect. Nausea occurred in two patients who had received meperidine $40 \mathrm{mg}$. Vomiting occurred in one patient who had received butorphanol $2 \mathrm{mg}$ and in two patients who had received meperidine $80 \mathrm{mg}$. One patient experienced tachycardia, hypotension and dizziness after a second dose of butorphanol $1 \mathrm{mg}$. This was felt to be due to hypovolaemia during a long labour. These signs and symptoms subsided promptly with the administration of intravenous fluids.

\section{Newborn Results}

Statistical analysis indicated that the mean of the one minute Apgar scores was significantly higher for the butorphanol $2 \mathrm{mg}$ group than for the meperidine $80 \mathrm{mg}$ group. The mean time to sustained respiration was significantly shorter for the butorphanol $2 \mathrm{mg}$ group than for the meperidine $80 \mathrm{mg}$ group. No additional significant differences were detected between means for other baby data variables (Table II).

The overall impression of the condition of 70 of the 81 babies (one set of (wins) was good or excellent.

Complications were encountered in four infants. Three of these were obstetrical problems. However, one infant had drug-related depression which briefly required tracheal intubation and ventilation with oxygen and reversal with naloxone. This infant's mother had received two doses of meperidine $80 \mathrm{mg}$.

The concentrations of butorphanol in neonatal blood approximated maternal concentrations as measured in six mothers and infants. Analysis by radioimmunoassay indicated that butorphanol crossed the placenta with a mean umbilical venous (neonatal) to maternal venous ratio of 0.84 (range, $0.4-1.4$ ) at delivery, 1.5 to 3.5 hours after intramuscular administration of a single or two successive doses of butorphanol $1 \mathrm{mg}$ or $2 \mathrm{mg}$ (Table III). The circulating metabolites of butorphanol, hydroxy-butorphanol and butorphanol glucuronide, which are all biologically inactive. were found in both maternal and foetal serum. The presence of these compounds in the foetus is felt to be due to placental or foetal metabolism of butorphanol rather than placental transfer (Table III).

The concentration of meperidine was measured in four mothers and their infants with similar observations. Analysis by gas chromotography showed that meperidine crossed the placenta with a mean umbilical venous (neonatal) to maternal venous ratio of 0.89 (range, 0.72 1.16) at delivery, at 0.85 to 3.6 hours after administration of a single $40 \mathrm{mg}$ dose or two successive $40 \mathrm{mg}$ doses of meperidine (Table III).

Although neuro-behavioural profiles such as those described by Scanion were not done, a general nursery survey was done for each infant. The four babies with complications were slow 
feeders initially, but all recovered without apparent sequelae.

\section{Discussion}

In spite of the preference of many for regional anaesthetics, systemic analgesics will continue to be needed during labour. Existing drugs and methods of use are not entirely satisfactory, mainly because of neonatal depression and obundation of the mother for these important events. In addition, traditionally it was felt that if the infant survived the immediate post-birth resuscitation period, drugs from the labour period were of little significance. Today, because of several studies utilizing neuro-behaviour profiles, we know that these drug effects may last for some time after birth. With this in mind, it would seem appropriate to look for new and perhaps superior analgesics, especially with regard to effect on the foetus.

In this study, butorphanol appeared to relieve the pain of labour at least as well as meperidine. Of the four groups studied, meperidine $40 \mathrm{mg}$ was the least effective with regard to pain relief.

The infant data with regard to Apgar scores and time to sustained respiration with the two high doses (butorphanol $2 \mathrm{mg}$ and meperidine $80 \mathrm{mg}$ ) are intriguing. Separate work by Nagashima ${ }^{10}$ and Kallos " has demonstrated that respiratory depression with morphine $10 \mathrm{mg}$ or meperidine 70 $\mathrm{mg}$ and butorphanol $2 \mathrm{mg}$ was equal at these nearly equi-analgesic levels. Above that dose the degree of respiratory depression produced by butorphanol did not increase as it did with meperidine and morphine. Our data with regard to A pgar scores and time to sustained respiration measurements failed to show any clear-cut separation between drugs in this study. While the time to onset of sustained respiration was longer with meperidine $80 \mathrm{mg}$ than with butorphanol 2 $\mathrm{mg}$. the reverse was true with meperidine $40 \mathrm{mg}$ and butorphanol $1 \mathrm{mg}$. This was no doubt due to various obstetrical factors rather than drugrelated respiratory depression. In only one infant whose mother had received two doses of meperidine $80 \mathrm{mg}$ did we clearly see respiratory depression in the infant, which was reversed by naloxone. The Apgar scores varied likewise; however, again obstetrical factors apparently were contributory. Apgar scores in all groups were generally good. Comparison of Apgar scores beyond this can be misleading because the test is basically not parametric.

These data suggest that butorphanol is as safe as meperidine at equi-analgesic doses under clinical circumstances and that obstetrical factors were undoubtedly significant determinants of the subjective and objective factors we measured and evaluated.

The lack of psychomimetic effects with butorphanol is encouraging. The principle problem with pentazocine, a similar compound, is the occurrerice of hallucinations, often at clinical doses. We saw no psychomimetic effects in our patients.

The authors feel that additional work with this compound in obstetrics is merited. We would suggest additional studies of placental transfer in animals and in man, neuro-behavioural studies on the newborns for several days after delivery and wide-spread clinical trials to assess the potential for psychomimetic phenomena, particularly in pregnant women.

\section{SUMmary}

Butorphanol tartrate $1 \mathrm{mg}$ and $2 \mathrm{mg}$ were compared in $\mathbf{8 0}$ normal mothers at term in a doubleblind study with meperidine hydrochloride $40 \mathrm{mg}$ and $80 \mathrm{mg}$ for the relief of pain in labour. Butorphanol was found to be as effective as meperidine in relieving pain in labour. The foetal condition, as measured by ECG monitoring, Apgar scores, time to sustained respiration, umbilical venous $\mathrm{H}^{+}(\mathrm{pH})$ and $\mathrm{PCO}_{2}$, and a general nursery survey were comparable for meperidine and butorphanol. No psychomimetic phenomena were seen. Assays indicated that both butorphanol and meperidine crossed the placenta. The mean concentration of butorphanol in neonatal serum was 0.84 times maternal serum at 1.5 to 3.5 hours after intramuscular administration of a single or two successive doses of butorphanol $1 \mathrm{mg}$ or $2 \mathrm{mg}$ to the mother. The mean concentrations for meperidine in neonatal serum was 0.89 times maternal serum at 0.85 to 3.6 hours after intramuscular administration of meperidine $40 \mathrm{mg}$ or $80 \mathrm{mg}$ to the mother. Neither analgesic caused severe depression of the infant except for one meperidine-treated case.

\section{RÉSUMÉ}

Les tartrate de butorphanol, à des doses de 1 et de $2 \mathrm{mg}$, a été comparé à la mépéridine (doses de 40 et de $80 \mathrm{mg}$ ) pour soulager les douleurs du travail dans un groupe de 80 parturientes en bonne santé, ceci dans le cadre d'une étude à double insu. Le butorphanol s'est avéré aussi 
efficace que la mépéridine pour soulager les douleurs du travail. L'évaluation des bébés (monitoring de l'ECG foetal, Apgar, début de la respiration régulière, $\mathrm{pH}$ et $\mathrm{PCO}_{2}$ du sang veineux du cordon et, enfin, évaluation générale en pouponnière) était comparable avec l'un et l'autre des agents. On n'a pas observé de phénomènes psycho-mimétiques.

Les analyses ont objectivé le passage transplacentaire des deux produits. La concentration sérique du nouveau-né en butorphanol était de 0.84 par rapport à celle de la mère, une heure et demie à trois heures et demie après l'administration à la mère d'une dose unique ou de deux doses successives de 1 à $2 \mathrm{mg}$, par voie intramusculaire. La concentration sérique retrouvée chez le nouveau-né, après administration de mépéridine, était de 0.89 par rapport à celle de la mère. Dans toute cette étude, nous n'avons observé une dépression respiratoire que chez un seul enfant (dont la mère avait reçu de la mépéridine).

\section{ACKNOWLEDGEMENT}

The authors wish to express their gratitude to Dr. R.D. Smyth, Director of Drug Metabolism and Pharmacokinetics of Bristol Laboratories, for providing the analytical data on butorphanol and meperidine.

\section{REFERENCES}

1. Harris, L.S. \& Pierson, A.K. Some narcotic antagonists in the benzomorphan series. J. Pharmacol. Exp. Ther. 143: 141 (1964).
2. Jasinskl, D.R., Martin, W.R., \& HoeldTKE, R.D. Effect of short- and long-term administration of pentazocine in man. Clin. Pharm. \& Ther, 11 : $385(1970)$.

3. Monkovic, I., Conway, T.T., Wong, H., PerRON, Y.C., Pachter, l.J., \& Belleau, B. Tolal synthesis and pharmacological activities of N-substituted 3,14-dihydroxymorphinans. J. Am. Chem. Soc. 5: 7910 (1973).

4. Pircio, A.W., Gylys, J.A., Cavanagh, R.L. BUYNISKI, J.P., \& BIERWAGEN, M.E. The pharmacology of butorphanol, a 3,14-dihydroxy. morphinan narcotic antagonist analgesic. Arch. Int. Pharmacodyn. Therap. 220: 231 (1976).

5. Cavanagh, R.L., Gylys, J.A., \& Bierwagen, M. E. Antitussive properties of butorphanol. Arch. Int. Pharmacodyn. Therap, 220:258 (1976).

6. DOBKIN, A.B., EAMKAOW, S., ZAK, S., \& Caruso, F.S. Butorphanol: a double-blind evaluation in post-operative patients with moderate or severe pain. Can. Anaesth. Soc. J. 21:600 (1974).

7. Tavakoli, M., Corssen, G., \& Caruso, F.S. Butorphanol and morphine: a double-blind comparison of their parenteral analgesic activity. Anesth. \& Analg. 55: 394 (1976).

8. Gilbert, M.S. Hanover, R.M., Movlan, D.S., \& Caruso, F.S. Comparison of the intramuscular analgesic activity of butorphanol and meperidine in post-operative patients. Clin. Pharm. \& Ther. 20: 359 (1976).

9. APGAR, V. A proposal for a new method of evaluation of the newborn infant. Anesth. \& Analg. 32: $260(1953)$.

10. Nagashima, H., Karamanian, A., Malovany, R., Radnay, P., Ano, M., Koerner, S, \& FoLDES, F.F. Respiratory and circulatory effects of intravenous butorphanol and morphine. Clin. Pharm. \& Ther. 19:738(1976).

11. KaLLOS, T. \& CARUSo, F.S. Respiratory effects of butorphanol. Abstracted. Clin. Pharm. \& Ther. 21: $107(1977)$. 